\title{
High affinity Recognition of a Phytophthora protein by Arabidopsis via an RGD motif
}

\author{
Virginie Senchou $^{\mathrm{a}, \mathrm{b}}$, Rob Weide ${ }^{\mathrm{b}}$, Antoine Carrasco ${ }^{\mathrm{a}}$, Huguette Bouyssou ${ }^{\mathrm{a}}$, Rafael Pont- \\ Lezica $^{\mathrm{a}}$, Francine Govers ${ }^{\mathrm{b}}$, and Hervé Canut ${ }^{\mathrm{a}, 1}$ * \\ ${ }^{\text {a} S u r f a c e s ~ C e l l u l a i r e s ~ e t ~ S i g n a l i s a t i o n ~ c h e z ~ l e s ~ V e ́ g e ́ t a u x, ~ U M R ~} 5546$ CNRS-Université Paul \\ Sabatier, BP17, 31326 Castanet Tolosan cedex, France \\ ${ }^{\mathrm{b}}$ Laboratory of Phytopathology, Wageningen University, Binnenhaven 5, 6709 PD \\ Wageningen, The Netherlands \\ Running title: RGD motif receptor in Arabidopsis thaliana \\ ${ }^{1}$ To whom correspondence should be addressed. Telephone 335621935 27; fax 335621935 \\ 02; E-mail canut@scsv.ups-tlse.fr \\ This paper is in memory of Antoine Carrasco
}

\begin{abstract}
The RGD tripeptide sequence, a cell adhesion motif present in several extracellular matrix proteins of mammalians, is involved in numerous plant processes. In plant-pathogen interactions, the RGD motif is believed to reduce the plant defense responses by disrupting adhesions between cell wall and plasma membrane. Photoaffinity cross-linking of $\left[{ }^{125} \mathrm{I}\right]$ azido-RGD heptapeptide in the presence of purified plasma membrane vesicles of Arabidopsis thaliana led to label incorporation into a single protein with an apparent molecular mass of $80 \mathrm{kDa}$. Incorporation could be prevented by excess RGD peptides, but also by the IPI-O protein, an RGD-containing protein secreted by the oomycete plant pathogen Phytophthora infestans. Hydrophobic Cluster Analysis revealed that the RGD motif of IPI-O (positions 53-56) is readily accessible for interactions. Single amino acid mutations in the RGD motif in IPI-O (of Asp ${ }^{56}$ into Glu or Ala) resulted in the loss of protection of the $80 \mathrm{kDa}$ protein from labelling. Thus, the interaction between the two proteins is mediated through RGD recognition and the $80 \mathrm{kDa}$ RGD-binding protein has the characteristics of a receptor for IPI-O. The IPI-O protein also disrupted cell wall - plasma membrane adhesions in plasmolysed $A$. thaliana cells whereas IPI-O proteins mutated in the RGD motif (D56A and D56E) did not.
\end{abstract}

Key words: cell signalling, RGD motif, plasma membrane, cell wall, Phytophthora infestans, Arabidopsis thaliana 


\section{Introduction}

The Arg-Gly-Asp (RGD) motif was originally identified as the site within fibronectin that mediates cell attachment [1]. Soon thereafter it was demonstrated that several other extracellular proteins containing an RGD motif play a role in cell adhesion processes in many different mammalian tissues via their RGD functional site. RGD receptors located in the plasma membrane are members of the integrin family, which connect the extracellular matrix (ECM) outside the cell with the actin-cytoskeleton inside the cell [2-4]. Integrins are also chosen by pathogens as targets for binding, and the RGD motif is present in surface proteins of several pathogens that attach to mammalian cells [5]. In plants, synthetic peptides containing the RGD motif can disrupt the adhesion between plasma membrane and cell wall [6-7] and can interfere with physiological processes thereby affecting, e.g., development [811], mechano-perception [12] and the interaction with microorganisms [13-15]. In particular, expression of cell wall associated defence responses triggered by fungal pathogens is dependent on adhesion between the plasma membrane and the plant cell wall [15]. The fact that these adhesions can be disrupted by RGD containing peptides suggests similarities between plant cell wall-plasma membrane interactions, and mammalian ECM-membranecytoskeleton continuum [16]. Despite the importance of these adhesions, the molecules engaged in the plant cell wall-membrane-cytoskeleton continuum are not known. Plants seem to lack orthologues of integrins or ECM proteins: in the Arabidopsis genome no open reading frames resembling such proteins have been found [17]. Because the plant cell wall is different in structure from the mammalian ECM, it is likely that the molecules involved in the structural continuity between the cytoskeleton and the wall are unique to plants [18].

Previously, we demonstrated that Arabidopsis thaliana contains plasma membrane proteins that can bind peptides containing the RGD motif [7]. We hypothesised that the high affinity RGD-binding sites at the plasma membrane may be the plants' counterparts of integrins and to further identify these membrane components we developed a photoaffinity method to cross-link an RGD-containing peptide to its potential targets on purified plasma membrane. We identified an $80 \mathrm{kDa}$ RGD-binding protein that is strongly selective towards the RGD sequence and show that this $80 \mathrm{kDa}$ plasma membrane protein functions as a receptor for the RGD-containing protein IPI-O from the oomycete plant pathogen Phytophthora infestans [19]. Finally, we show that the IPI-O protein promotes the disruption of cell wall - membrane contacts in A. thaliana.

\section{Experimental procedures}

\section{Plant material and purification of plasma membrane}

Etiolated seedlings of $A$. thaliana ecotype Columbia were grown in $1000 \mathrm{~mL}$ Erlenmeyer flask containing $150 \mathrm{~mL}$ of Murashige and Skoog basal medium with the addition of sucrose to $10 \mathrm{~g} . \mathrm{L}^{-1}$, and harvested after two weeks of culture, leading to 20-30 g (fresh weight) of plant material [20]. Cell suspension culture of $A$. thaliana (ecotype Columbia, cell line 112) was performed as before [20]. Eight-day-old cells (exponential phase of growth) were used in all experiments. The purified plasma membrane vesicles were isolated from microsomes of $A$. thaliana seedlings by preparative free-flow electrophoresis. The purity was assessed both by the determination of marker enzyme activities and by the reactivity of immunological probes [20]. Based on the measurement of ATPase latency, the plasma membrane fraction appeared to consist essentially of cytoplasmic side-in vesicles. 


\section{Peptide synthesis and labelling}

The synthesis and iodination of three peptides, YGRGDSP, YGRGESP and YGDGRSP, was performed as previously described [7].

The photoaffinity probe synthesis started with the peptide AGRGDSP done automatically by stepwise Fmoc-t-butyl solid phase synthesis in a Synergy Applied Biosystems peptide synthesiser. The N-terminal Fmoc-group was removed and, before acid cleavage of the peptide-resin, the photoreactive heterobifunctional reagent $\mathrm{N}$ hydroxysuccinimidyl-4-azidosalicylic acid (Pierce) was added to the $\mathrm{NH}_{2}$ group of the Ala residue according to the manufacturer's instructions. Then the side-chain protective groups were removed. Crude synthetic peptides were purified by reverse-phase high-pressure liquid chromatography (HPLC). The purified peptides were characterised by amino acid composition, sequence analysis and laser desorption time of flight by mass spectrometry on a Lasermat spectrometer.

Iodination of the $N$-(4-azido-salicylyl) AGRGDSP heptapeptide was carried out in the dark, at room temperature in a safety device equipped with charcoal filter. In a microfuge tube, $28 \mathrm{MBq}$ of $\mathrm{Na}\left[{ }^{125} \mathrm{I}\right](0.35 \mathrm{nmol})$ in $10 \mu \mathrm{L}$ of solution at $\mathrm{pH} 8\left({ }^{125} \mathrm{I}-629 \mathrm{GBq} \mathrm{mg}^{-1}\right.$, from NEN life science) were added to $10 \mu \mathrm{L}$ of $0.3 \mathrm{M}$ phosphate buffer $\mathrm{pH} 7.4$ containing 0.28 $\mathrm{nmol}$ of the peptide. The reaction was started by the addition of $3 \mu \mathrm{L}$ chloramine $\mathrm{T}(54 \mu \mathrm{g}$ $\mathrm{mL}^{-1}$ ) in phosphate buffer; three subsequent additions of $3 \mu \mathrm{L}$ chloramine $\mathrm{T}$ were performed at $1 \mathrm{~min}$ intervals. The reaction was stopped $5 \mathrm{~min}$ after the last addition of chloramine $\mathrm{T}$ by adding $10 \mu \mathrm{L}$ of tyrosine $\left(1 \mathrm{mg} \mathrm{mL}^{-1}\right)$ in phosphate buffer. The iodinated peptide was purified by reverse-phase HPLC. Routinely, radioactivity incorporation of $30 \%$ into the monoiodinated $N$-(4-azido-salicylyl) peptide was obtained.

\section{Binding and photoaffinity assays}

The binding of radiolabelled YGRGDSP heptapeptide to purified plasma membrane vesicles was performed as previously described [7]. The photolabelling of plasma membrane vesicles with the mono-iodinated $N$-(4-azidosalicylyl) AGRGDSP heptapeptide was carried out in $50 \mathrm{mM}$ BTP (bis-tris propane) $(\mathrm{pH} \mathrm{7.0,} \mathrm{HCl})$ containing $0.25 \mathrm{M}$ sucrose as follows. Incubation mixtures contained plasma membrane vesicles $\left(100 \mu \mathrm{g}\right.$ of protein) and $\left[{ }^{125} \mathrm{I}\right]-\mathrm{N}-(4-$ azidosalicylyl) peptide $(28 \mathrm{kBq}, 0.35 \mathrm{pmol})$ in a total volume of $0.1 \mathrm{~mL}$. The samples were incubated for $5 \mathrm{~min}$ on ice, and then photo illuminated for $30 \mathrm{sec}$ on ice with high UV intensity light $(312 \mathrm{~nm}$ ) from a $176 \mathrm{~W}$ Spectroline lamp (Spectronics), situated $15 \mathrm{~cm}$ from the sample. When additives were present, as indicated in the legends of the figures, the samples were pre-incubated for 10 min on ice. Membranes were then centrifuged at $4{ }^{\circ} \mathrm{C}$ for $30 \mathrm{~min}$ at $45000 \mathrm{xg}$. The pellets were washed twice in the incubation buffer and resuspended in Laemmli sample buffer. After SDS-PAGE, the $11 \%$ acrylamide gels were dried under vacuum at $70{ }^{\circ} \mathrm{C}$ for $2 \mathrm{~h}$ and then placed in contact with Hyperfilm MP (Amersham Pharmacia Biotech) for 3 days to 1 week at $-70^{\circ} \mathrm{C}$.

\section{Production of IPI-O protein and mutant IPI-O protein}

The ipiO1 ORF (GenBank accession L23939), encoding the mature IPI-O protein without the putative signal sequence [19], was cloned into the expression vector pMALc (maltose binding protein -MBP- vectors, New England Biolabs) resulting in pPIN18c. Within the ipiOl ORF, two individual mutations in the RGD tripeptide motif were obtained using 
PCR-mediated mutagenesis and Amplitaq polymerase (Perkin Elmer) with pPIN18c as template. The primers were designed to result in mutation of the aspartic acid residue at position 56 in either an alanine (D56A) or a glutamic acid (D56E). The PCR products were cloned in the pMALc expression vector, and mutations were confirmed by DNA sequencing. Expression of the pMALc based plasmids was induced by adding IPTG. Only the soluble fractions from the E. coli extracts were used to purify the recombinant MBP-IPI-O protein and recombinant mutated proteins MBP-IPI-O-D56A and MBP-IPI-O-D56E on amylose resin [21]. The purified proteins were used as competitors in the binding or photoaffinity assays.

\section{Amino acid sequencing of recombinant IPI-O protein and hydrophobic cluster analysis}

To obtain some primary amino acid sequences of the recombinant MBP-IPI-O protein, a Coomassie Brillant Blue R250-stained band was excised from a gel after SDS-PAGE. After reduction and alkylation the protein was in-gel digested [22]. MS-MS data were obtained using a Q-TOF tandem mass spectrometer and electrospray ionisation source (Q-TOF, Micromass). The sample was loaded as a mixture of enzyme digests of MBP-IPI-O protein into a nanoelectrospray needle. The instrument was calibrated with polypropylene glycol according to the manufacturer's specifications.

Hydrophobic cluster analysis (HCA) [23] was performed to predict the structural features of IPI-O along the deduced amino acid sequence. HCA plots were generated using the program HCA-Plot2 (Doriane, Paris).

\section{Results}

\section{The RGD motif in the Phytophthora infestans IPI-O protein is exposed to the surface}

The deduced amino acid sequence of the $P$. infestans ipiO gene [19] revealed the presence of an arginine-glycine-aspartic acid (RGD) tripeptide motif located at positions 5456, a putative N-terminal signal sequence (positions 1-21) suggesting that the IPI-O protein is secreted, and a potential $N$-glycosylation site (NTSD) at positions 66-69 (fig. 1A). A hydrophobic cluster analysis (HCA) plot was drawn in order to predict the structural features of the IPI-O protein and, in particular, to evaluate the accessibility of the RGD sequence as a potential recognition motif (fig. 1B). Because typical shapes of clusters are associated with definite secondary structures, HCA plots are well suited to recognize amphiphilic $\alpha$-helices and $\beta$-strands; in this respect, IPI-O mainly consists of $\beta$-sheet structures. The large hydrophobic cluster at the N-terminal part of the protein corresponds to the signal peptide. The RGD motif (positions 54-56) occurs in a well exposed region and is thus suspected to be readily accessible to the solvent. Also the $N$-glycosylation site (NTSD; positions 66-69) appeared well-exposed in a hydrophilic loop and could actually be glycosylated.

\section{IPI-O competes with RGD peptides in binding to plasma membrane vesicles}

To be able to test whether the RGD tripeptide motif in IPI-O can be recognized by plant receptors, we produced a recombinant IPI-O protein and used this as a competing ligand in binding assays. Part of the ipiO gene, i.e. the part encoding the mature protein without signal peptide, was subcloned in the E. coli expression vector pMAL-c. Expression should result in the production of a fusion protein (designated MBP-IPI-O) containing at the Nterminus the maltose-binding protein (MBP). To verify its identity, trypsin digests were 
analysed by Q-TOF tandem mass spectrometry. One selected peptide exhibited the sequence AVSSNLNTAVNYASTSKIR which corresponds exactly to the amino acids at positions 21 to 39 in IPI-O (fig. 1A). In the same way, we produced recombinant IPI-O proteins mutated in their RGD tripeptide motif. The individual mutations of Asp were generated in order to keep (MBP-IPI-O-D56E) or to abolish (MBP-IPI-O-D56A) the negative charge of the aspartic acid residue.

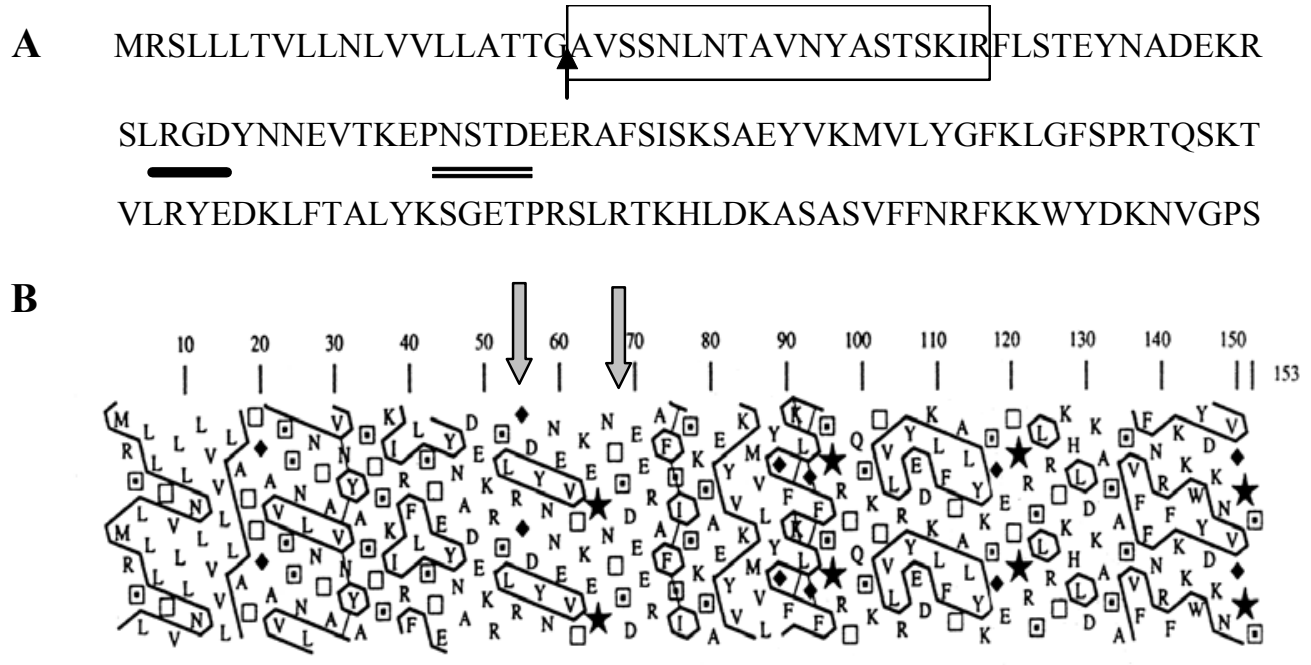

Figure 1

Deduced amino acid sequence and hydrophobic cluster analysis (HCA) plot of the IPI-O protein. A - The deduced amino acid sequence of the ipi-O1 gene (accession $\mathrm{N}^{\circ}$ L23939) showing the putative signal sequence cleavage site (black arrow), RGD cell adhesion motif (black bar), a putative $N$-glycosylation site (double underline) and the recovered sequence tag from the recombinant MBP-IPI-O1 protein by Q-TOF MS/MS analysis (box). B - HCA plot of IPI-O1. Hydrophobic residues (F, I, L, M, V, W, Y) are encircled to form hydrophobic clusters. Special symbols are used for G ( $\bullet$ ), S (square with dot), P ( $\star$ ) and T ( ) that often occur in loops. The RGD cell adhesion motif (positions 54-56) and the putative $N$-glycosylation site (positions 66-69) are indicated by arrows.

A

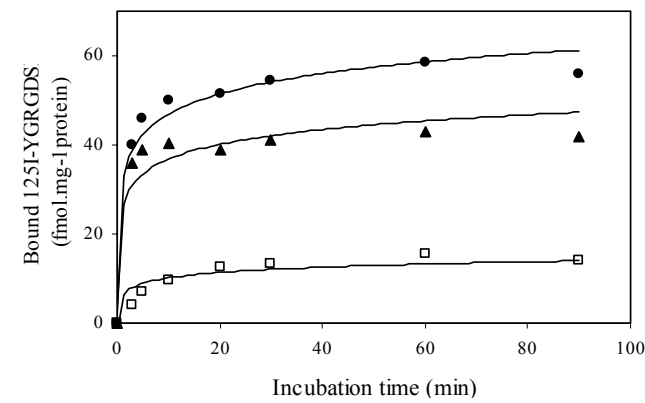

B

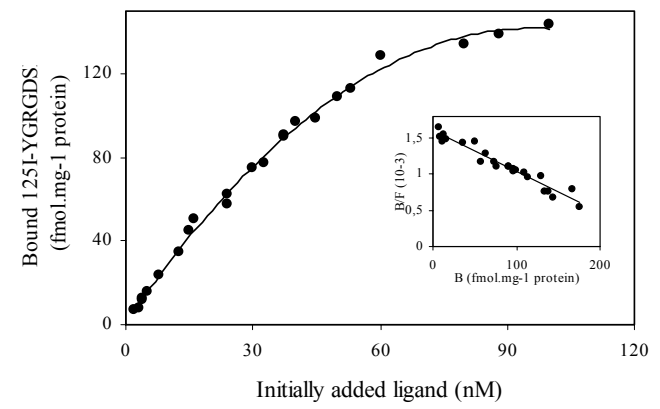

Figure 2

Kinetics and saturability of the binding of ${ }^{125} \mathrm{I}$ labelled heptapeptide (YGRGDSP) to purified plasma membrane from A. thaliana seedlings. A Association kinetics $(\bullet)$ were determined by adding labelled heptapeptide $(0.15 \mathrm{pmol})$ to plasma membrane vesicles (50 $\mu \mathrm{g}$ of protein) and incubating the samples at $24^{\circ} \mathrm{C}$ for increasing amounts of time. Non-specific binding $(\boldsymbol{\Delta})$ was measured by adding a 1000 -fold excess of unlabelled heptapeptide simultaneously with the labelled ligand at time 0 . The amount of specific binding $(\square)$ was determined by subtracting non-specific binding from total binding. B - Saturability of the binding of ${ }^{125} \mathrm{I}-$ labelled heptapeptide: increasing amounts of cold heptapeptide to $0.15 \mathrm{pmol}$ of labelled heptapeptide were added to membranes (50 $\mu \mathrm{g}$ of protein) and incubated for $30 \mathrm{~min}$ at $24^{\circ} \mathrm{C}$. Non-specific binding was determined in the presence of $0.15 \mathrm{nmol}$ unlabelled heptapeptide. The specific binding data shown were analysed to calculate the Scatchard plot (inset). 
The association of the $\left[{ }^{125} \mathrm{I}\right]-$ YGRGDSP to its binding site was detected shortly after starting the incubation with purified plasma membrane from etiolated $A$. thaliana seedlings. It reached a maximum after $20 \mathrm{~min}$ and remained steady up to $90 \mathrm{~min}$ (fig. 2A). Specific binding after $20 \mathrm{~min}$ averaged $15-25 \%$ of the total binding. A rapid dissociation was observed following the addition of unlabelled RGD-heptapeptide (data not shown). The binding of RGD-heptapeptide to plasma membrane vesicles was saturable (fig. 2B). The Scatchard plot indicated one class of high affinity binding sites with $\mathrm{K}_{\mathrm{d}}=80 \mathrm{nM}$ and $\beta_{\max }=270 \mathrm{fmol} . \mathrm{mg}^{-1}$ protein.

The plasma membrane-localised binding site for RGD recognition exhibits strong selectivity in terms of the peptide sequences that are recognized efficiently (fig. 3). All the synthetic RGD-peptides, YGRGDSP, AGRGDSP and RGDS are equally effective inhibitors of ligand binding, and the concentration required to achieve $50 \%$ inhibition was $80 \mathrm{nM}$. Fibronectin, an adhesive glycoprotein localised in the extracellular matrix of animal cells and containing an RGD motif, required higher concentrations $(450 \mathrm{nM})$. Interestingly, the purified recombinant MBP-IPI-O protein required the lowest concentration to achieve $50 \%$ inhibition of binding, i.e. $6 \mathrm{nM}$. In contrast, the mutated MBP-IPI-O-D56A and -D56E proteins, as well as the maltose binding protein alone (MBP), required 1000-fold higher concentrations to partially reduce ligand binding. Finally, the YGRGESP peptide (substitution of aspartic acid with glutamic acid), the YGDGRSP (inversion of the RGD sequence) and a soybean lipoxygenase exhibiting an RGD motif were not recognized at all. These results indicate that the $A$. thaliana seedlings have a highly sensitive and selective perception system for peptides and proteins containing the RGD motif.

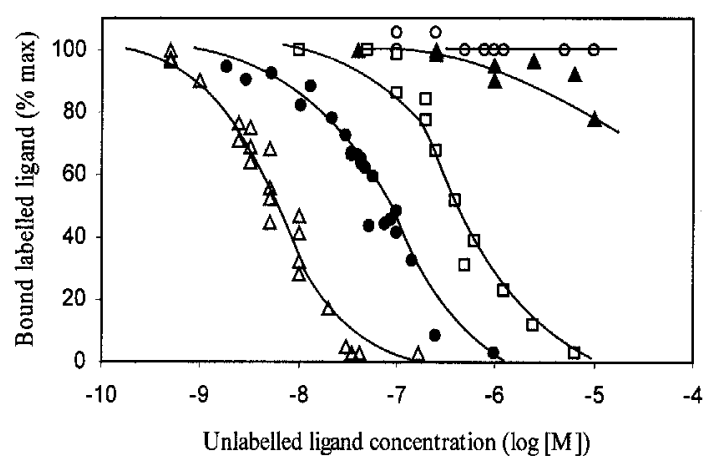

Figure 3. Competitive inhibition of binding of ${ }^{125} \mathrm{I}-$ labelled heptapeptide to $A$. thaliana plasma membrane by unlabelled peptides and proteins. Labelled heptapeptide YGRGDSP was incubated with plasma membrane vesicles in the presence of increasing amounts of the MBP-IPI-O recombinant protein $(\triangle)$, YGRGDSP or AGRGDSP or $\underline{\text { RGDS }}$ peptides (O), human fibronectin ( $\square$ ), mutant proteins MBP-IPI-O-D56A or MBP-IPI-OD56E or maltose binding protein ( $\boldsymbol{\Delta}$ ) and YGRGESP or YGDGRSP peptides or soybean lipoxygenase $(\bigcirc)$. Binding assays were carried out as described in Figure 2.

\section{An RGD-binding protein from Arabidopsis plasma membrane is a receptor for IPI-O}

To identify the proteins that may be involved in RGD binding activity at the plant cell surfaces, plasma membrane vesicles from $A$. thaliana seedlings were labelled by photoirradiation in the presence of $\left[{ }^{125} \mathrm{I}\right]-\mathrm{N}(4$-azidosalicylyl)AGRGDSP heptapeptide. The majority of the label was associated with one protein of $80 \mathrm{kDa}$ (fig. 4, lanes 1 and 6). The label migrating at the front of the gel represents free photoaffinity label which is non covalently associated with protein and released upon electrophoresis. Labelling of the $80 \mathrm{kDa}$ protein could be efficiently competed by RGD-containing peptides (lanes 2 and 3 ). In contrast, the YGDGRSP (inversion of the RGD sequence) and YGRGESP (substitution of aspartic acid with glutamic acid) peptides did not compete for labelling (lanes 4 and 5). The labelling of the $80 \mathrm{kDa}$ protein was also abolished by the presence of the recombinant MBP-IPI-O protein (fig. 4). To quantify cross-linking, gel slices corresponding to the $80 \mathrm{kDa}$ polypeptide were excised and $\gamma$ counted. Thus, a 300 -fold excess of recombinant MBP-IPI-O protein to the 
photoaffinity probe (100 $\mathrm{nM}$, i.e. 15-times the $\mathrm{Kd}$ value) blocked cross-linking to the $80 \mathrm{kDa}$ polypeptide by $71 \%$ and $63 \%$ (lanes 7 and 10 , respectively). In contrast, the mutated MBPIPI-O-D56A and -D56E proteins had no effect (lanes 8 and 9). So, the $80 \mathrm{kDa}$ plasma membrane protein seems to be a receptor for IPI-O and that binding of IPI-O to this binding site indeed occurs through its intrinsic RGD tripeptide motif.

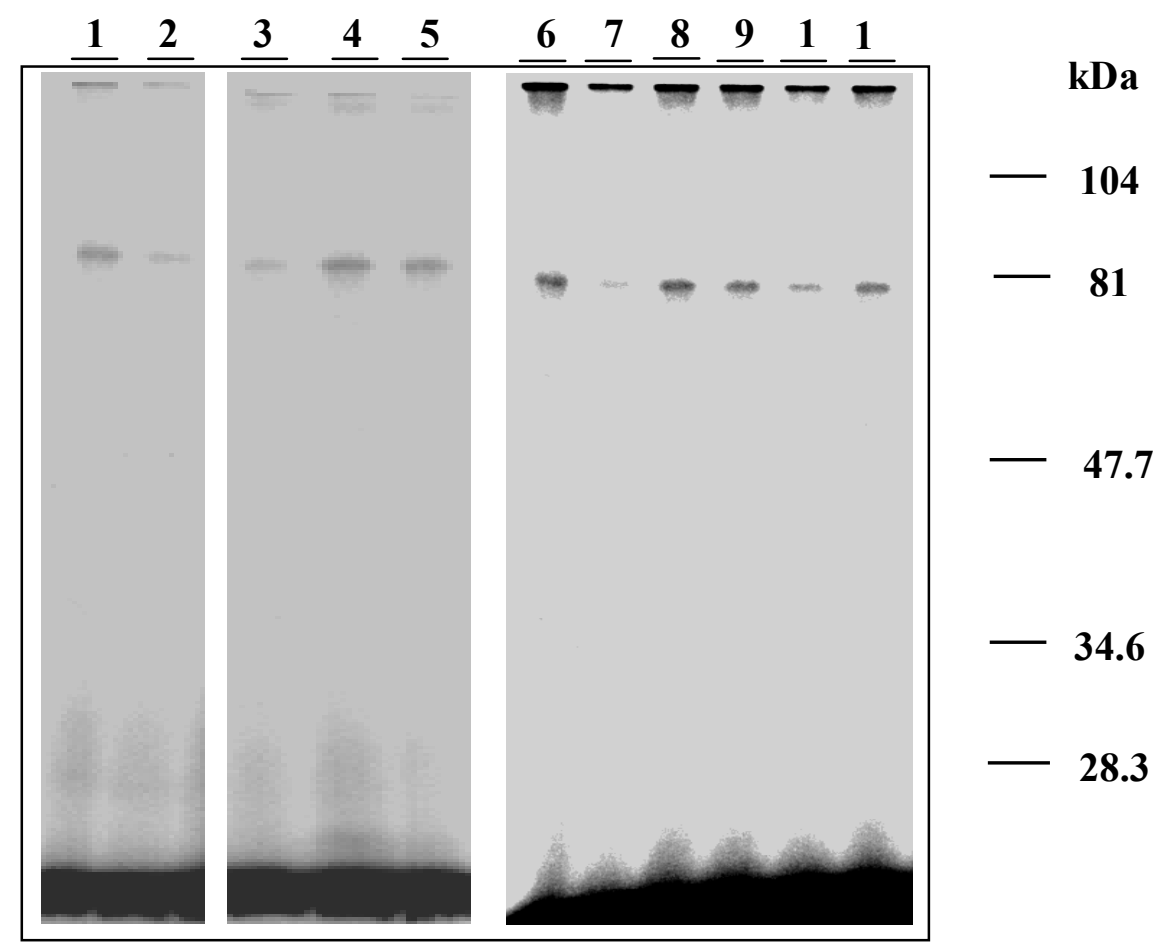

Figure 4 Photoaffinity labelling of plasma membrane protein from $A$. thaliana with an azido RGD-heptapeptide derivative and effects of the wild type and mutant MBP-IPI-O proteins. Plasma membrane proteins were separated in SDS-11\% polyacrylamide gels. Lanes 1 and 6 are the labelling patterns observed after autoradiography when the radioiodinated RGD-photoaffinity probe [N-(4-azido-salicylyl) AGRGDSP heptapeptide] was photolysed as described under "experimental procedures". In lane 2, the AGRGDSP or RGDS peptide $(1 \mathrm{nmole}-10 \mu \mathrm{M})$ was included in the photolysis medium. In lane 3 , the YGRGDSP peptide (1 nmole $10 \mu \mathrm{M})$ was present. In lanes 4 and 5, the YGDGRSP and YGRGESP heptapeptides (1 nmole - $10 \mu \mathrm{M})$ were present respectively. In lanes 7 and 10 , the recombinant MBP-IPI-O protein $(0.1 \mathrm{nmole}-1 \mu \mathrm{M})$ was included in the photolysis medium. In lanes 8 and 9 , the mutant proteins MBP-IPI-O-D56A and -D56E $(0.1 \mathrm{nmole}-1 \mu \mathrm{M})$ were present respectively. In lane 11 , the maltose binding protein ( $\mathrm{MBP}-1 \mathrm{nmole}-10 \mu \mathrm{M})$ was present. One hundred micrograms of protein were deposited in each lane.

\section{IPI-O disrupts attachments between plasma membrane and cell wall}

To examine whether IPI-O resembles RGD peptides in disrupting cell wall - plasma membrane attachments [7] we plasmolysed undifferentiated cells from a suspension culture of A. thaliana and observed the plasma membrane - cell wall attachments by microscopy, in the absence or presence of recombinant MBP-IPI-O proteins. Plasmolysis was induced in the absence of MBP-IPI-O with the addition of $0.5 \mathrm{M} \mathrm{CaCl}_{2}$. Once plasmolysis had started, the plasma membrane separated from the cell wall but at some points the contact between cell wall and membrane was maintained resulting in concave pockets (fig. 5A). In contrast, cells plasmolysed in the presence of MBP-IPI-O showed a convex form: the plasma membrane uniformly separated from the cell wall giving spherical protoplasts (fig. 5B), whereas mutated MBP-IPI-O-D56A and-D56E proteins or MBP alone had no disrupting effect (fig. 5C). 
These observations suggest that the RGD tripeptide motif in IPI-O is responsible for disrupting plasma membrane - cell wall attachments.
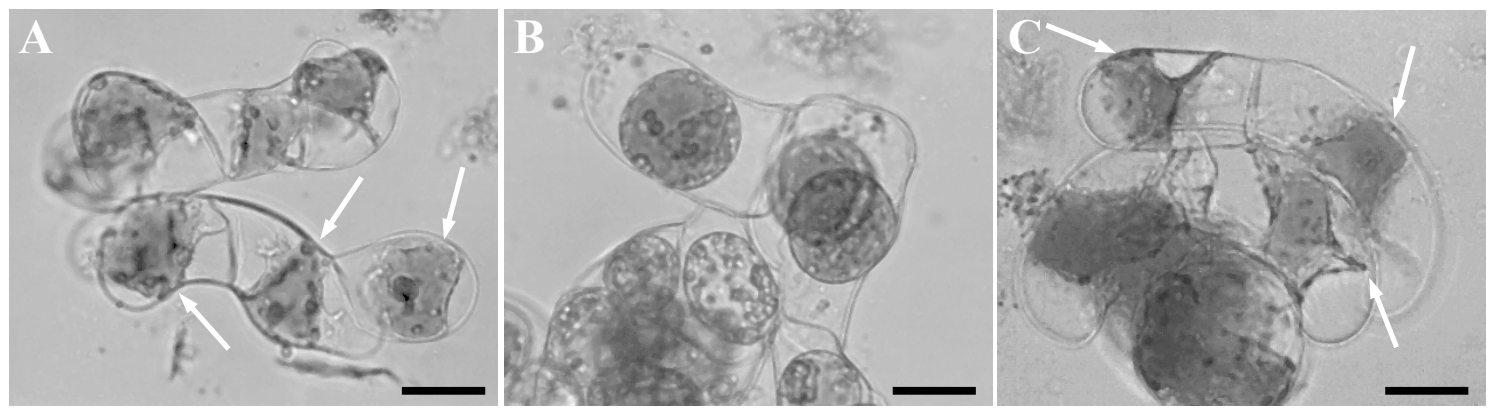

Figure 5. Effects of the wild type and mutant MBP-IPI-O proteins on plasma membrane - cell wall adhesions. A. thaliana cells from a suspension culture were harvested by decantation and stained with neutral red. (A)Upon addition of $0.3 \mathrm{M} \mathrm{CaCl}_{2}$, the plasmolysed cells revealed plasma membrane - cell wall adhesions (arrows). (B)- The cells were incubated (10 $\mathrm{min})$ with the MBP-IPI-O recombinant protein $(0.1 \mu \mathrm{M})$ and plasmolysed. The plasma membrane separated from the cell wall to make spherical protoplasts and a convex plasmolysis. A similar pattern of plasmolysis has been obtained with YGRGDSP peptide (14); (C)- In the presence of mutant proteins MBP-IPI-O-D56A or -D56E $(0.1 \mu \mathrm{M})$ or MBP protein $(3 \mu \mathrm{M})$, the plasma membrane and the wall remained attached to give a concave plasmolysis as in panel A. A YGRGESP peptide has been shown to be also uneffective in disrupting wall to membrane adhesions (14). Bars $=20 \mu \mathrm{m}$.

\section{Discussion}

The interaction of RGD peptides with plasma membrane vesicles from Arabidopsis thaliana seedlings involves a single or predominant class of binding sites with a dissociation constant of approximately $80 \mathrm{nM}$. The receptors responsible for that binding activity have not been identified: plants may possess adhesion molecules that to some extent are homologous to those in animals, but attempts to identify the proteins immunologically or to isolate their encoding genes by cross hybridization were not successful [24-26]. In this report we describe a non-biased approach to identify such (a) receptor(s). It is purely based on the function of the putative plant adhesion molecules, i.e. RGD-mediated protein-protein interactions. We modified an RGD-containing peptide with the photoreactive, heterobifunctional cross-linking reagent, $N$-hydroxysuccinimidyl-4-azidosalicylic acid and found that ultraviolet irradiation of plasma membrane vesicles in the presence of the photoaffinity probe resulted in labelling of an $80 \mathrm{kDa}$ membrane protein.

The characteristics of the $80 \mathrm{kDa}$ protein identified by photoaffinity cross-linking are similar to those of the RGD binding sites identified in binding assays. First, we detected photoprobe incorporation into only a single plasma membrane protein in accordance with a single high affinity binding site identified in the binding assays. Second, photoprobe incorporation was prevented by the addition of excess of RGD-containing peptides, the same peptides that act as competitors for the binding site. Third, the smallest modifications that render the RGD sequence incapable of interacting with RGD binding sites, i.e. the glutamic for aspartic acid and the inversion of the tripeptide sequence, were also inactive in preventing photoprobe incorporation. Finally, the $80 \mathrm{kDa}$ plasma membrane protein is an RGD binding protein capable of strong selectivity towards the RGD sequence. Only few RGD dependent protein-protein interactions have been described in plants [27-28], and their involvement in cell wall-membrane attachments remains to be elucidated. In contrast, the wall-associated kinases (WAKs) are bound to both the plasma membrane and the extracellular matrix [29], but these links are not mediated by an RGD sequence. 
In mammalians, a wide range of unrelated pathogens bind, via the RGD sequence of their own cell surface proteins, to integrin receptors found on many cell types. Such recognition is a general strategy that allows microorganisms to modulate infectivity and to regulate toxicity towards host cells [5]. Recent observations report that RGD peptides interfere with the activation of plant defence responses [13-15]. Thus, RGD recognition through plant proteins may occur and RGD-containing proteins from phytopathogenic microorganisms may act as pathogenicity factors. So far, very few RGD-containing proteins from plant pathogens have been described. We know of one virus protein, the precursor of G1 and G2 glycoproteins of the tomato spotted wilt virus [30]; two fungal proteins, ECP5 from Cladosporium fulvum [31] and Ptr ToxA from Pyrenophora tritici-repentis [14]; and one oomycete protein, IPI-O from Phytophthora infestans [19]. ECP5, Ptr ToxA and IPI-O are secreted proteins and also G1 and G2 are located outside the virus namely in the virus envelope membrane. For the present study we choose to test IPI-O as ligand for two reasons. First, the ipiO gene is specifically expressed during the growth of the pathogen in planta (in planta induced - ipi) at the edge of the lesion and in the tips of the invading hyphae [32]. Second, of the plant pathogens known to secrete an RGD-containing protein, P. infestans is the only one that has some kind of interaction with $A$. thaliana. P. infestans can penetrate epidermal cells and the plant responds to this penetration with a rapid hypersensitive response [33]. A. thaliana is fully resistant to $P$. infestans and is thus considered to be a non-host. In this study we demonstrated that the $80 \mathrm{kDa}$ plasma membrane protein is a putative receptor for IPI-O and that recognition of IPI-O occurs through its intrinsic RGD: the individual mutations of $\mathrm{Asp}^{56}$ resulted in the total loss of IPI-O recognition by the $80 \mathrm{kDa}$ membrane protein.

From the structural prediction of IPI-O, the RGD motif appeared well exposed and therefore accessible for interaction with others proteins. Indeed, RGD-binding sites at the plasma membrane of $A$. thaliana attached IPI-O with the highest affinity, i.e. $6 \mathrm{nM}$. This affinity is 75-times higher than that of fibronectin, an adhesive glycoprotein localised in the extracellular matrix of animal cells. The huge difference in affinity between fibronectin and IPI-O suggests that the exposure of the RGD motif in IPI-O is determinant in the recognition by a plant receptor. For instance, plant lipoxygenases of which several isoforms exhibit an RGD motif, do not bind to the $A$. thaliana plasma membrane. In our binding assays IPI-O is recognised with the highest affinity, a feature we can effectively expect for a natural ligand when compared to synthetic peptides, and IPI-O may therefore be considered as a prototype RGD ligand for plant receptors despite the fact that no IPI-O homologues have been identified in plants nor in any other organism. These searches are limited however, to homology in secondary structure and it can not be excluded that plants contain an endogenous RGD ligand that structurally resembles IPI-O. All together, the results show that the RGD receptor interacts specifically with IPI-O via the RGD sequence and, suggest a role for the two proteins, and for their RGD-mediated recognition, in plant-pathogen interactions.

The importance of plasma membrane-cell wall adhesions during pathogen penetration was highlighted by the study of Mellersh and Heath [15]. When the rust fungus Uromyces vignae attacked its natural host, cowpea, RGD-containing peptides reduced the expression of cell wall-associated defence responses during fungal penetration. The effect of RGD peptides correlated with disruption of the physical contacts between plasma membrane and cell wall. However, in non-host pea cells, the plasma membrane remained attached to the cell wall. Also, when powdery mildew fungi attacked host or non-host cowpea plants, the plasma membrane - cell wall attachments appeared to be stronger than in non-infected plants. An increase in adhesion has also been reported for powdery mildew-barley interactions [34]. 
These observations suggest the existence of multiple plasma membrane-cell wall interacting molecules with different functions in plants [15]. In the present study we showed that incubation of $A$. thaliana cells with IPI-O also disrupts the plasma membrane-cell wall attachments resulting in a convex form of plasmolysis. No adhesion sites could be distinguished confirming the full activity of the RGD sequence of IPI-O and suggesting a role of its RGD motif in disrupting the adhesion sites. When $P$. infestans invades potato, its natural host plant, ipiO is transiently expressed in planta, with the highest mRNA levels in the early stages of infection [32]. Therefore, IPI-O may have the ability to reduce the plasma membrane-cell wall attachments during the onset of the interaction by competing with endogenous plant cell wall proteins, supporting a role for IPI-O as a pathogenicity factor. In conclusion, the results described here provide the first evidence for RGD-dependent recognition of a pathogen ligand by a plant putative receptor. The RGD-binding protein located at the plasma membrane of $A$. thaliana is also the first element to further understand the effects of exogenous RGD-containing peptides in plant processes. In the next steps we will exploit the high affinity ligand IPI-O as a tool to clone the receptor gene. This opens the possibility to elucidate the structure of the first RGD-binding plant receptor and to unravel the significance of the specific RGD-dependent recognition of IPI-O by an A. thaliana plasma membrane protein.

\section{Acknowledgments}

We thank Pr. P. Rougé (IPBS, Toulouse) for the structural analysis of IPI-O, Dr. P. Ferrara and J. Capdevielle (Sanofi-Synthelabo, Toulouse) for mass spectrometry facilities, Dr C. Pieterse for constructing the ipiO expression vector pPIN18-c. V.S. gratefully acknowledges financial support by the Netherlands-French bilateral exchange programme "van Gogh".

\section{References}

1. Pierschbacher M.D. and Ruoslathi E. (1984) Cell attachment activity of fibronectin can be duplicated by small synthetic fragments of the molecule. Nature, 309: 30-33

2. Hynes R.O. (1987) Integrins: a family of cell surface receptors. Cell 48: 549-550

3. Schwartz M.A., Schaller M.D. and Ginsberg M.H. (1995) Integrins: emerging paradigms of signal transduction. Ann. Rev. Cell Dev. Biol. 11: 549-599

4. Dedhar S. and Hanningan G.E. (1996) Integrin cytoplasmic interactions and bidirectional transmembrane signalling. Curr. Opin. Cell Biol. 8: 657-669

5. Isberg R.R. and Tran Van Nhieu G. (1994) Binding and internalization of microorganisms by integrin receptors. Trends Microbiol. 2: 10-14

6. Henry C.A., Jordan J.R., and Kropf D.L. (1996) Localized membrane-wall adhesions in Pelvetia zygotes. Protoplasma 190: 39-52

7. Canut H., Carrasco A., Galaud J.P., Cassan C., Bouyssou H., Vita N., Ferrara P. and PontLezica R. (1998) High affinity RGD-binding sites at the plasma membrane of Arabidopsis thaliana links the cell wall. Plant J. 16: 63-71 
8. Schindler M., Meiners S. and Cheresh D.A. (1989) ) RGD-dependent linkage between plant cell wall and plasma membrane: consequences for growth. J. Cell Biol. 108: 1955-1965

9. Corrëa A., Staples R.C. and Hoch H.C. (1996) Inhibition of thigmostimulated cell differentiation with RGD peptides in Uromyces germlings. Protoplasma 194: 91-102

10. Barthou H., Petitprez M., Brière C., Souvré, A. and Alibert G. (1999) RGD-mediated membrane-matrix adhesion triggers agarose-induced embryoid formation in sunflower protoplasts. Protoplasma $206: 143-151$

11. Diaz-Sala C., Garrido G. and Sabater B. (2002) Age-related loss of rooting capability in Arabidopsis thaliana and its reversal by peptides containing the Arg-Gly-Asp (RGD) motif. Physiol. Plant. 114: 601-607

12. Wayne R., Staves M.P., and Leopold A.C. (1992) The contribution of the extracellular matrix to gravisensing in characean cell. J. Cell Sci. 101: 611-623

13. Kiba A., Sugimoto M., Toyoda K., Ichinose Y., Yamada T. and Shiraishi T. (1998) Interaction between cell wall and plasma membrane via RGD motif is implicated in plant defense responses. Plant Cell Physiol. 39: 1245-1249

14. Meinhardt S.W., Cheng W., Kwon C.Y., Donohue C.M. and Rasmussen, J.B. (2002) Role of the arginyl-glycyl-aspartic motif in the action of Ptr ToxA produced by Pyrenophora tritici-repentis. Plant Physiol, 130: 1545-1551

15. Mellersh D.G. and Heath M.C. (2001) Plasma membrane - cell wall adhesion is required for expression of plant defense responses during fungal penetration. Plant Cell 13: 413-424

16. Wyatt S.E. and Carpita N.C. (1993) The plant cytoskeleton-cell-wall continuum. Trends Cell Biol. 3: 413-417

17. The Arabidopsis Genome Initiative. (2000) Analysis of the genome sequence of the flowering plant Arabidopsis thaliana. Nature 408: 796-815

18. Reuzeau C. and Pont-Lezica R. (1995) Comparing plant and animal extracellular matrixcytoskeleton connections - are they alike? Protoplasma 186: 113-121

19. Pieterse C.M.J., van West P., Verbakel H.M., Brassé P.W.H.M., van den Berg-Velthuis G.C. and Govers F. (1994) Structure and genomic organization of the ipiB and ipiO gene clusters of Phytophthora infestans. Gene 138: 67-77

20. Bardy N., Carrasco A., Galaud J.P., Pont-Lezica R. and Canut, H. (1998) Free-flow electrophoresis for fractionation of Arabidopsis membranes. Electrophoresis 19: 1145-1153

21. Kellerman O.K. and Ferenci T. (1982) Maltose binding protein from E. coli. Methods Enzymol. 90: 459-463

22. Rosenfeld J., Capdevielle J., Guillemot J.C. and Ferrara P. (1992) In-gel digestion of proteins for internal sequence analysis after one- or two-dimensional gel electrophoresis. Anal. Biochem. 203: 173-179 
23. Gaboriaud C., Bissery V., Benchetrit T. and Mornon J.P. (1987) Hydrophobic cluster analysis: an efficient new way to compare and analyse amino acid sequences. FEBS Lett. 224: $149-155$

24. Faik A., Labouré A.M., Gulino D., Mandaron P. and Falconet D. (1998) A plant surface protein sharing structural properties with animal integrins. Eur. J. Biochem. 253: 552-559

25. Laval V., Chabannes M., Carrière M., Canut H., Barre A., Rougé P., Pont-Lezica R. and Galaud J.P. (1999) A family of Arabidopsis plasma membrane receptors presenting animal beta-integrins domains. Biochim. Biophys. Acta 1435: 61-70

26. Nagpal P. and Quatrano R.S. (1999) Isolation and characterization of a cDNA clone from Arabidopsis thaliana with partial sequence similarity to integrins. Gene 230: 33-40

27. Faro C., Ramalho-Santos M., Vieira M., Mendes A., Simoes I., Andrade R., Verissimo P., Lin X., Tang J. and Pires E. (1999) Cloning and characterization of cDNA encoding cardosin A, an RGD-containing plant aspartic proteinase. J. Biol. Chem. 274: 28724-28729

28. Garcia-Gomez B.I., Campos F., Hernandez M. and Covarrubias A.A. (2000) Two bean cell wall proteins more abundant during water deficit are high in proline and interact with a plasma membrane protein. Plant J. 22: 277-288

29. Kohorn B.D. (2000) Plasma membrane-cell wall contacts. Plant Physiol. 124: 31-38

30. Kormelink R., de Haan P., Meurs C., Peters D. and Goldbach R. (1992) The nucleotide sequence of the mRNA segment of tomato spotted wilt virus, a bunyavirus with two ambisense RNA segments. J. Gen. Virol. 73: 2795-2804

31. Laugé R., Goodwin P.H., de Wit P.J.G.M. and Joosten M.H.A.J. (2000) Specific HRassociated recognition of secreted proteins from Cladosporium fulvum occurs in both host and non-host plants. Plant J. 23: 735-745

32. van West P., de Jong A.J., Judelson H.S., Emons A.M.C. and Govers F. (1998) The hypersensitive response is associated with host and nonhost resistance to Phytophthora infestans. Fungal Genet. Biol. 23: 126-138

33. Vleeshouwers V.G.A.A., van Dooijeweert W., Govers F., Kamoun S. and Colon L.T. (2000) The hypersensitive response is associated with host and nonhost resistance to Phytophthora infestans. Planta 210: 853-864

34. Lee-Stadelmann O.Y., Bushnell W.R. and Stadelmann E.J. (1984) Changes in plasmolysis form in epidermal cells of Hordeum vulgare infected by Erysiphe graminis: evidence for increased membrane-wall adhesion Can. J. Bot. 62: 1714-1723 